\title{
Endocardite Infecciosa em Criança com Comunicação Interventricular: Relato de Caso
}

\author{
Infective Endocarditis in Child with Interventricular \\ Communication: A Case Report \\ Camila de Holanda Carlos ${ }^{1}$, Anabel Góes Costa ${ }^{2}$, Maria Lúcia Duarte ${ }^{3}$ \\ ${ }^{1}$ Serviço de Pediatria do Hospital Santa Izabel; ${ }^{2}$ Serviço de Cardiologia Pediátrica do \\ Hospital Santa Izabel; ${ }^{3}$ Serviço de Ecocardiografia do Hospital Santa Izabel; Salvador, \\ Bahia, Brasil
}

Correspondence addresses:

Dra. Anabel Góes Costa

anabelgc@terra.com.br

Received: April 17, 2019

Revised: May 31, 2019

Accepted: June 8, 2019

Published: June 28, 2019

Data Availability Statement: All relevant data are within the paper and its Supporting Information files.

Funding: This work was the result of authors' initiative. There was no support of research or publication funds.

Competing interests: The authors have declared that no competing interests exist.

Copyright

(C) 2019 by Santa Casa de Misericórdia da Bahia. All rights reserved.

ISSN: 2526-5563
Endocardite infecciosa é uma afecção causada por invasão de microorganismos no endocárdio ou tecido valvar cardíaco. Apesar de incomum na população pediátrica, é importante a identificação e o tratamento imediatos devido a alta morbi-mortalidade. Este trabalho relatou o caso de uma criança de 7 anos portadora de cardiopatia congênita, submetida a procedimento dentário sem indicação de profilaxia por antibiótico que foi diagnosticada com endocardite infecciosa.

Palavras-chave: Endocardite Infecciosa; Profilaxia por Antibiótico; Doença Cardíaca Congênita.

Infective endocarditis is a condition caused by invasion of microorganisms in the endocardium or cardiac valve tissue. Although uncommon in the pediatric population, prompt identification and treatment are important because of its significant morbidity and mortality. The authors reported a case of infective endocarditis in a pediatric patient, that despite having a congenital heart disease and underwent a dental procedure, had no indication for antibiotic prophylaxis.

Keywords: Infective Endocarditis; Antibiotic Prophylaxia; Congenital Heart Disease.

\section{Introdução}

A endocardite infecciosa (EI) é uma patologia no endocárdio e/ou valvas do coração que envolve formação de trombos (vegetação) e pode danificar o tecido endocárdico ou valvar.

É incomum na faixa etária pediátrica e apresenta alta morbi-mortalidade. A incidência anual atinge de 0,05 a 0,12 casos por 1.000 admissões pediátricas e a taxa de mortalidade geral é aproximadamente de 5\%. Em torno de 35\% a 60\% das crianças com EI apresenta doença cardíaca congênita (DCC), que é fator de risco conhecido para o desenvolvimento da endocardite nesta população. ${ }^{1,2}$

A extração ou cirurgia dentária é o procedimento mais comumente associado a infecção, seguindo-se de cirurgias gastrintestinais, biliares, geniturinárias, do trato respiratório superior e cirurgias cardíacas com circulação extracorpórea. 
Nesse trabalho relatamos o caso de criança portadora de comunicação interventricular com endocardite infecciosa adquirida após procedimento odontológico.

\section{Relato de Caso}

M.L.M.A, 7 anos, apresentando febre vespertina e noturna associada a perda ponderal há 15 dias. Após 10 dias evoluiu com dor em hipocôndrio direito acompanhada de dispneia. Procurou pediatra assistente que solicitou hemograma e raio $\mathrm{X}$ de tórax, sendo diagnosticada pneumonia e iniciado tratamento com amoxicilina-clavulanato.

Apresentou melhora da febre nas primeiras 24 horas, porém no $5^{\circ}$ dia de uso do antibiótico não apresentava melhora significativa dos sintomas. Foi solicitado ecocardiograma que evidenciou vegetação em valvas tricúspide e pulmonar quando então a menor foi trazida para a emergência pediátrica dessa instituição.

\section{História Patológica Pregressa}

Comunicação interventricular ampla, parcialmente ocluída, sem uso de medicações (suspensas há 2 anos por cardiologista assistente). Extração dentária há 1 mês. Nega internamentos anteriores.

\section{Ecocardiograma Transtorácico (ecoTT)}

Valva Pulmonar: espessada, presença de imagens hiperecogênicas aderidas em uma de suas válvulas, compatível com vegetação. Insuficiência de grau discreto ao Doppler.

Septo interventricular: comunicação perimembranosa trabecular, com extensão para via de saída aórtica, medindo em torno de $1.2 \mathrm{~cm}$, com formação de aneurisma do septo membranoso na sua face ventricular direita, com dois orifícios de saída e significativo shunt esquerda-direita ao color. Presença de imagens hiperecogênicas irregulares, móveis e pediculadas no pertuito da comunicação interventricular, projetando-se para o ventrículo direito (com área de aproximadamente $1.83 \mathrm{~cm}^{2}$ ). Observa-se ainda continuidade dessas imagens em parede da via de saída do ventrículo direito e na valva pulmonar (compatível com vegetação). Sem imagens sugestivas de abscessos. Câmara atrial esquerda com importante aumento. Ventrículo esquerdo com dilatação de grau moderado. Presença de membrana subvalvar aórtica em via de saída do ventrículo esquerdo com gradiente máximo de $8 \mathrm{mmHg}$. Derrame pericárdico discreto (Figuras 1 e 2).

Iniciada antibioticoterapia por 6 semanas com ceftriaxone e oxacilina, e realização de ecoTT semanal. Feita correção cirúrgica após 6 semanas de antibioticoterapia e hemoculturas negativas, sem intercorrências e com bom resultado.

\section{Discussão}

O presente relato trata de uma paciente portadora de DCC (comunicação interventricular e membrana subvalvar aórtica) que evoluiu com grande vegetação, um mês após ser submetida a procedimento odontológico sem profilaxia para endocardite infecciosa.

Nos últimos 50 anos, a American Heart Association (AHA) tem proposto vários regimes de profilaxia a fim de evitar o estabelecimento da EI. ${ }^{3-5}$ A partir dos guidelines de 2007, a recomendação é que a prevenção seja realizada apenas no grupo de alto risco, com a justificativa de não haver evidência suficiente de que a profilaxia com antibióticos forneça benefício na prevenção de EI em pacientes de moderado e baixo risco. Esse conceito foi corroborado pelo protocolo de 1997 que trazia o conceito de que a maioria dos casos de endocardite não era decorrente de procedimentos invasivos, mas de episódios aleatórios de bacteremia transitória causada por hábitos rotineiros de higiene bucal, como a escovação, o uso de fio dental ou até mesmo por meio da mastigação. ${ }^{6}$

Desta forma, de acordo com as novas diretrizes da AHA, a profilaxia é indicada para pacientes portadores de condições cardíacas como endocardite infecciosa prévia, valvas cardíacas protéticas, aquisição de disfunção valvar pós-transplante cardíaco, portadores de 
Figura 1. Corte paraesternal de eixo curto com imagem de vegetação (VEG) aderida na via de saída do ventrículo direito.

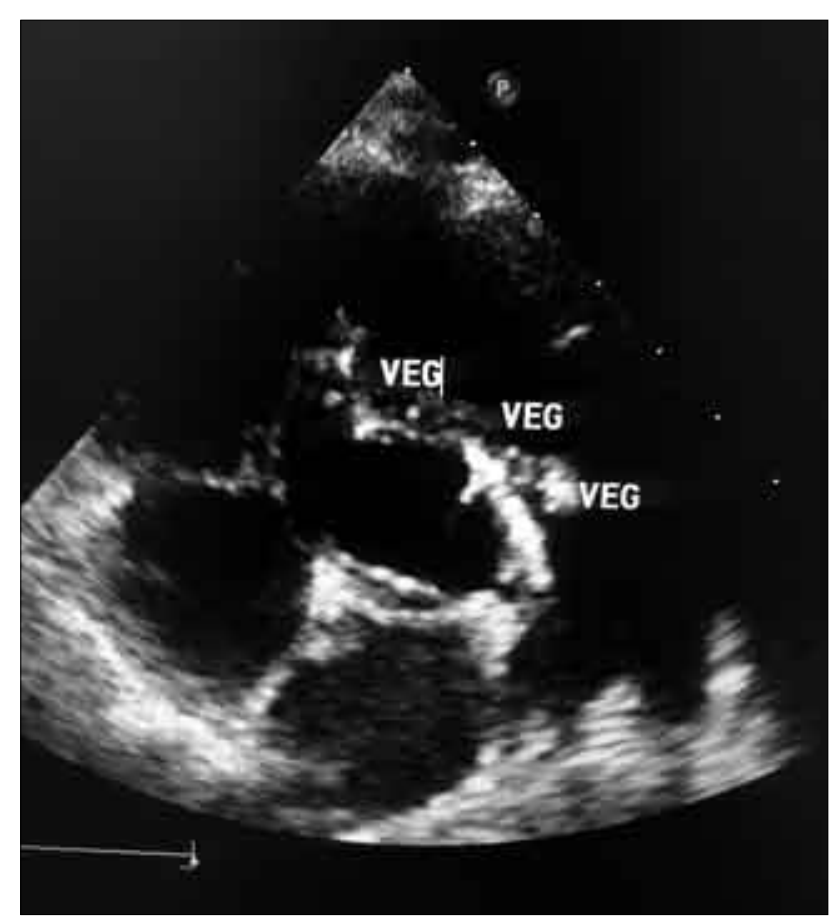

Figura 2. Corte paraesternal de eixo longo mostrando imagem de vegetação no pertuito da comunicação interventricular.

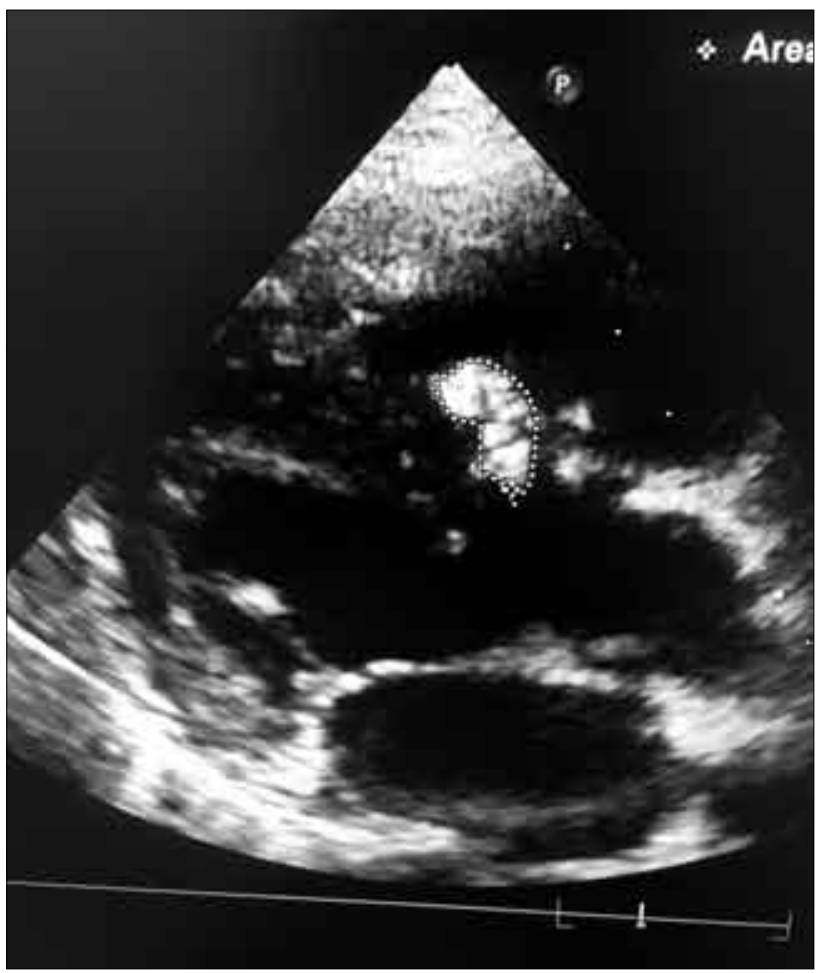

cardiopatia congênita ciagnogênica complexa, derivações cirúrgicas sistêmico-pulmonares ou correção cirúrgica de DCC com lesão residual. Tais diretrizes causam muitas controvérisas na literatura atual, devido ao conflito de suas recomendações com a conduta em uso pela maioria dos profissionais, além de confrontar diferentes realidades entre países desenvolvidos e em desenvolvimento.

\section{Referências}

1. Pasquali SK, He X, Mohamad Z, Mccrindle BW, Newburger JW, et al., Trends in endocarditis hospitalizations at US children's hospitals: impact of the 2007 American Heart Association Antibiotic Prophylaxis

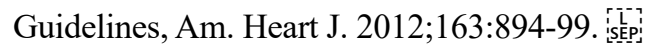

2. Sun L-C, et al., Risk factors for infective endocarditis in children with congenital heart diseases - A nationwide population-based case control. Int J Cardiol 2017. http://dx.doi.org/10.1016/j.ijcard.2017.08.009.

3. Wilson W, Taubert KA, Gewitz M, et al. Prevention of infective endocarditis: guidelines from the American Heart Association: Rheumatic Fever, Endocarditis, and Kawasaki Disease Committee, Council on Cardiovascular Disease in the Young, and the Council on Clinical Cardiology, Council on Cardiovascular Surgery and Anesthesia, and the Quality of Care and Outcomes Research Interdisciplinary Working Group. Circulation 2007;116:1736.

4. Nishimura RA, Otto CM, Bonow RO, et al. AHA/ACC guideline for the management of patients with valvular heart disease: a report of the American College of Cardiology/American Heart Association Task Force on Practice Guidelines. J Am Coll Cardiol 2014;63:e57.

5. Nishimura RA, Otto CM, Bonow RO, et al. 2017 AHA/ACC Focused Update of the 2014 AHA/ACC Guideline for the Management of Patients With Valvular Heart Disease: A Report of the American College of Cardiology/American Heart Association Task Force on Clinical Practice Guidelines. J Am Coll Cardiol 2017.

6. Dajani AS, Taubert KA, Wilson W, Bolger AF, Bayer A, et al. Prevention of bacterial endocarditis: recommendations by the American Heart Association. Clin Infect Dis 1997;25(6):1448-58. 